\title{
Pemilihan Daerah Pelayanan Sampah di Bandung Utara Berdasarkan Parameter Daerah Prioritas SNI-19-2454-2002
}

\author{
Lutfi Adhari $^{{ }^{*}}$, Yulianti Pratama ${ }^{2}$, Nico Halomoan ${ }^{3}$ \\ 1,2,3 Jurusan Teknik Lingkungan Fakultas Teknik Sipil dan Perencanaan Institut Teknologi Nasional \\ Jalan PHH.Mustofa No.23, Bandung 40124, Indonesia \\ *Koresponden email: kupatadhari@gmail.com
}

Diterima: 29 September 2020

Disetujui: 8 Oktober 2020

\begin{abstract}
The North Bandung Service Area (WP) is a waste WP which has a service level in 2017 of $79.5 \%$, there are still some unserved areas. Each North Bandung WP has different regional characteristics, so according to previous research, service areas were formed using the cluster analysis method to classify regions based on regional characteristics in order to support the target service level of $90 \%$. The purpose of this planning is for the development of previous research by planning the existing priority service area waste management system as an effort to achieve the target of waste services in WP North Bandung. The selection of priority areas is based on the parameters for determining priority areas for SNI 19-2454-2002. This research is expected to solve the problem of waste management system in WP North Bandung.
\end{abstract}

Keywords: North Bandung, cluster analisys, waste management, service area, priority areas, SNI 19-2454-2002

\begin{abstract}
Abstrak
Wilayah Pelayanan (WP) Bandung Utara merupakan WP sampah yang memiliki tingkat pelayanan tahun 2017 sebesar 79,5\%, masih terdapat beberapa daerah yang belum terlayani. Setiap WP Bandung Utara memiliki karakteristik daerah yang berbeda, sehingga menurut penelitian sebelumnya dibentuk daerah pelayanan menggunakan metode cluster analysis untuk mengelompokan daerah berdasarkan karakteristik daerahnya demi menunjang target tingkat pelayanan sebesar 90\%. Tujuan perencanaan ini untuk pengembangan atas penelitian sebelumnya dengan merencanakan sistem pengelolaan sampah daerah pelayanan prioritas yang telah ada sebagai upaya mencapai target pelayanan sampah di WP Bandung Utara. Pemilihan wilayah prioritas ini berdasarkan parameter penentuan daerah prioritas SNI 19-24542002. Penelitian ini diharapkan dapat mengatasi permasalahan sistem pengelolaan sampah di WP Bandung Utara.

Kata Kunci : analisis klaster, Bandung Utara, daerah prioritas, pengelolaan sampah, wilayah pelayanan, SNI 19-2454-2002
\end{abstract}

\section{Pendahuluan}

Berdasarkan data dari PD Kebersihan Kota Bandung, tingkat pelayanan sampah Wilayah Pelayanan (WP) Bandung Utara tahun 2017 sebesar 79,5\%. Target tingkat pelayanan Kota Bandung pada tahun yang sama yaitu sebesar $90 \%$, sehingga diperlukan upaya perbaikan tingkat pelayanan untuk wilayah Bandung Utara agar tercapai target tingkat pelayanan yang telah ditetapkan [1]. Upaya yang akan dilakukan untuk mencapai target pelayanan Kota Bandung yaitu dengan merencanakan Sistem Pengelolaan Sampah (SPS) dari daerah pelayanan yang menjadi prioritas dari penelitian sebelumnya, yaitu dengan cara mengidentifikasi kesesuaian karakteristik daerah dan dari timbulan sampah yang dihasilkannya.

Berdasarkan hasil penelitian yang dilakukan [2] yaitu Identifikasi Daerah Pelayanan Sistem Pengelolaan Sampah di Wilayah Pelayanan Bandung Utara Menggunakan Metode Cluster Analysis, WP Bandung Utara di bagi menjadi 6 daerah pelayanan (cluster), berdasarkan pengelompokan parameter daerah pelayanan yang tercantum dalam SNI-19-2454-2002 tentang Tata Cara Teknik Pengelolaan Sampah Perkotaan dengan menggunakan metoda analisa cluster. Parameter daerah pelayanan yang dimaksud pada SNI-19-2454-2002 tersebut berdasarkan karakteristik daerahnya, sehingga daerah yang memiliki karakteristik yang sama dikelompokkan pada satu cluster [3].

Hasil dari pembentukan daerah pelayanan (cluster) ini perlu adanya pengembangan penelitian dalam rangka upaya untuk mencapai target tingkat pelayanan sampah yang telah ditentukan. Pengembangan penelitian yang dimaksud ialah merencanakan SPS di daerah pelayanan yang telah 
dibentuk dari hasil penelitian sebelumnya. Hasil studi lanjutan ini diharapkan target tingkat pelayanan yang ditetapkan sebesar 90\% dapat tercapai.

\section{Metode Penelitian}

Sistem pengelolaan sampah yang direncanakan harus disesuaikan dengan karakteristik daerah perencanaannya. Hal ini bertujuan agar perencanaan pengelolaan sampah yang direncanakan efektif dan efesien dari segi pewadahan, pengumpulan, dan pemindahan sampahnya. Pemilihan daerah prioritas diperlukan untuk menentukan daerah yang paling urgen dilakukan perencanaan atas dasar aspek-aspek penentuan daerah prioritas. Pada SNI 19-2454-2002 dimana daerah prioritas ini ditentukan berdasarkan pembetukan daerah pelayanan yang telah dilakukan oleh septiani, (2018). Perencanaan yang akan dilakukan yaitu di Kelurahan terpilih berdasarkan penentuan daerah prioritas pada [3]. Adapun alur metode penelitian dapat dilihat pada Gambar 1.

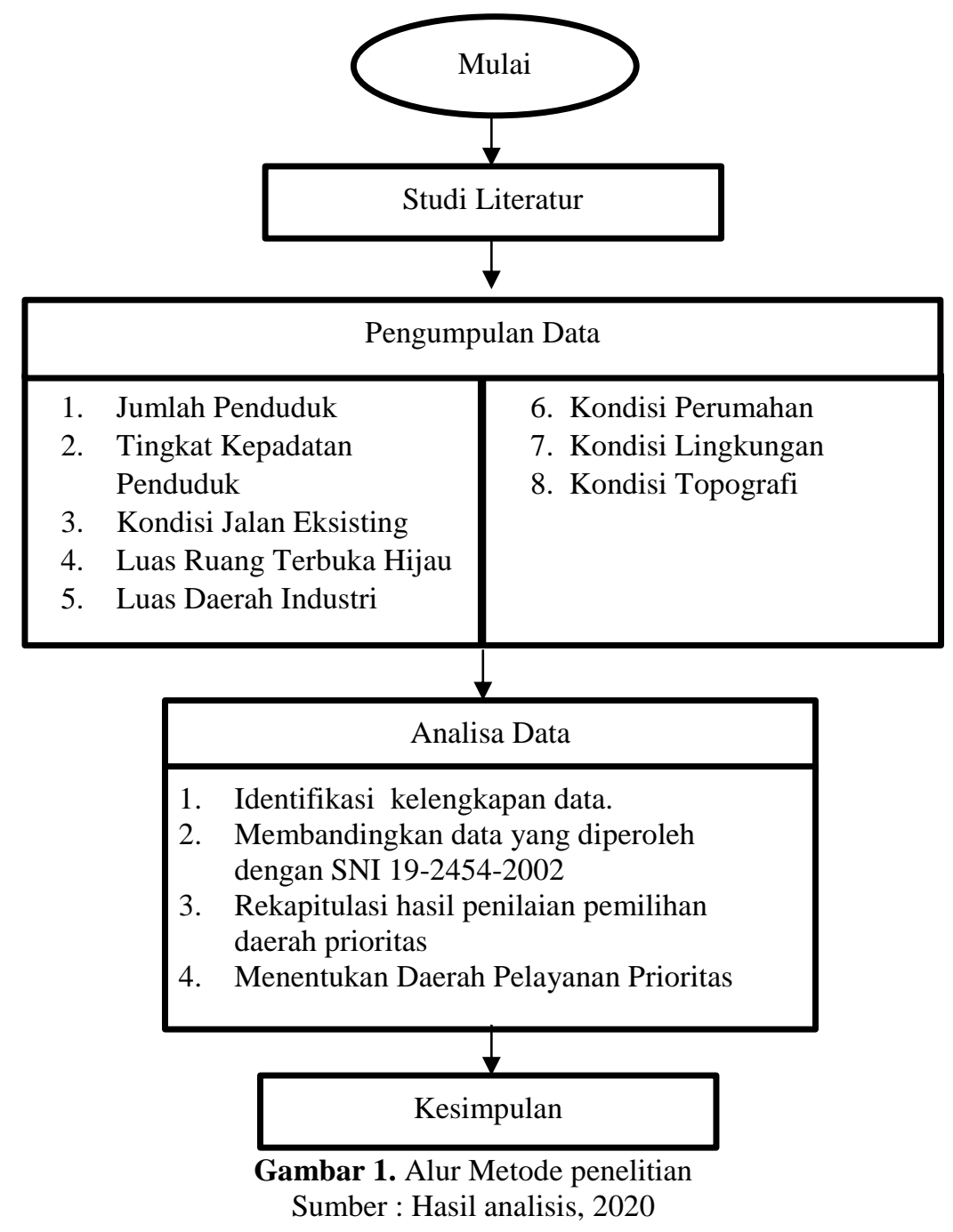

Pemilihan daerah pelayanan (cluster) prioritas di WP Bandung Utara menggunakan parameter penentuan daerah prioritas pada SNI 19-2454-2002 tentang Tata Cara Teknik Pengelolaan Sampah Perkotaan. Setiap parameter memiliki nilai dan pembobotan yang semakin tinggi nilai maka daerah tersebut semakin prioritas. Tabel 1 - Tabel 10 merupakan parameter untuk menentukan daerah pelayanan sampah yang prioritas.

\section{Parameter Kepadatan Penduduk}

Parameter kepadatan penduduk didasarkan pada SNI 19-2454-2002 tentang Tata Cara Teknik Pengelolaan Sampah Perkotaan. Menurut [4] menyatakan bahwa semakin tinggi kepadatan penduduk maka semakin prioritas daerah tersebut, dikarenakan semakin banyak timbulan sampah yang akan dihasilkan. Daerah dengan kepadatan penduduk tinggi merupakan daerah prioritas. Penilaiannya dapat dilihat pada Tabel 1. 
Tabel 1. Parameter kepadatan penduduk

\begin{tabular}{lc}
\hline \multicolumn{1}{c}{ Kriteria Penilaian } & Skor \\
\hline Rendah (50-100 jiwa/Ha) & 1 \\
Sedang $(100-300$ jiwa/Ha) & 2 \\
Tinggi $(>300$ jiwa/Ha) & 3 \\
\hline \multicolumn{2}{c}{ Sumber : SNI 19-2454-2002 }
\end{tabular}

\section{Parameter Jalan Arteri}

Berdasarkan penentuan daerah prioritas yang tertera pada SNI 19-2454-2002 jalan arteri menjadi salah satu acuan untuk menetukan daerah prioritas. Menurut [4] mengatakan bahwa semakin lebar jalan arteri maka daerah tersebut berada dalam suatu kota sehingga semakin prioritas. Berikut penilaian skoring pada parameter jalan arteri dapat dilihat pada Tabel 2.

Tabel 2. Parameter jalan arteri

\begin{tabular}{lc}
\hline \multicolumn{1}{c}{ Kriteria Penilaian } & Skor \\
\hline Rendah $(0 \mathrm{~m}-580,083 \mathrm{~m})$ & 1 \\
Sedang $(580,084 \mathrm{~m}-1160,166 \mathrm{~m})$ & 2 \\
Tinggi $(1160,167 \mathrm{~m}-1740,249 \mathrm{~m})$ & 3 \\
\hline \multicolumn{2}{c}{ Sumber : Hasil pengolahan data, 2020}
\end{tabular}

Penentuan kriteria penilaian ditentukan berdasarkan ketersediaan data di lapangan dengan membagi 3 standar kelas penilaian yang didapat dengan cara membandingkan data terbesar dan terkecil. Selanjutnya data dibagi dengan jumlah kelas yang akan dibuat. Semakin tinggi skor mengindikasikan daerah tersebut semakin prioritas

\section{Parameter Ruang Terbuka Hijau (RTH)}

Menurut SNI 19-2452 RTH menjadi salah satu faktor untuk penentuan daerah prioritas. Semakin luas suatu RTH maka daerah tersebut semakin tidak prioritas. Hal ini dikarenakan pada RTH yang luas berarti permukiman masyarakat semakin rendah maka timbulan sampahnya semakin rendah. Tingginya skor mengindikasikan bahwa daerah tersebut semakin prioritas. Berikut penilaian skoring pada parameter luas RTH dapat dilihat pada Tabel 3.

Tabel 3. Parameter luas RTH

\begin{tabular}{lc}
\hline \multicolumn{1}{c}{ Kriteria Penilaian } & Skor \\
\hline Rendah $(0 \mathrm{Ha}-30,315 \mathrm{Ha})$ & 3 \\
Sedang $(30,316 \mathrm{Ha}-60,631 \mathrm{Ha})$ & 2 \\
Tinggi $(60,631 \mathrm{Ha}-90,947 \mathrm{Ha})$ & 1 \\
\hline \multicolumn{2}{c}{ Sumber : Hasil pengolahan data, 2020}
\end{tabular}

Penentuan kriteria penilaian berdasarkan ketersediaan data di lapangan. Data dibagi ke dalam 3 standar kelas penilaian yang didapat dengan cara membandingkan data terbesar dan terkecil. Data selanjutnya dibagi dengan jumlah kelas yang akan dibuat.

\section{Parameter Luas Industri}

Berdasarkan penentuan daerah prioritas yang tertera pada SNI 19-2454-2002 luas wilayah industri menjadi salah satu acuan untuk menentukan daerah prioritas. Semakin luas daerah industri maka semakin besar pula sampah yang akan dihasilkan. Kegiatan industri akan menghasilkan sampah yang artinya semakin luas wilayah industri maka semakin besar skornya sehingga daerah tersebut semakin prioritas. Tabel 4 merupakan penilaian skoring untuk parameter luas industri.

Tabel 4. Parameter luas industri

\begin{tabular}{lc}
\hline \multicolumn{1}{c}{ Kriteria Penilaian } & Skor \\
\hline Rendah $(0 \mathrm{Ha}-2,476 \mathrm{Ha})$ & 1 \\
Sedang $(2,747 \mathrm{Ha}-5,492 \mathrm{Ha})$ & 2 \\
Tinggi $(5,493 \mathrm{Ha}-8,238 \mathrm{Ha})$ & 3 \\
\hline \multicolumn{2}{c}{ Sumber : Hasil pengolahan data, 2020}
\end{tabular}

Penentuan kriteria penilaian ditentukan berdasarkan ketersediaan data di lapangan. Data dibagi ke dalam 3 standar kelas penilaian yang didapat dengan cara membandingkan data terbesar dan terkecil. Data selanjutnya dibagi dengan jumlah kelas yang akan dibuat. 


\section{Parameter Perdagangan dan Jasa}

Suatu daerah perdagangan dan jasa kegiatannya pasti menghasilkan sampah maka semakin luas daerah perdagangan dan jasa semakin besar pula timbulan sampah yang dihasilkannya. Sehingga semakin besar luas daerah perdangan jasanya daerah tersebut semakin prioritas. Pembuatan standar kelas diperlukan untuk menetukan daerah prioritasnya, standar kelas dibuat dengan cara membandingkan nilai terbesar dan terkecil yang selanjutnya dibagi dengan jumlah kelas yang akan dibuat. Tingginya skor mengindikasikan bahwa daerah tersebut semakin prioritas. Tabel 5 merupakan penilai skoring untuk parameter perdagangan dan jasa.

Tabel 5. Parameter perdagangan dan jasa

\begin{tabular}{cc}
\hline Kriteria Penilaian & Skor \\
\hline Rendah $(1,253 \mathrm{Ha}-20,439 \mathrm{Ha})$ & 1 \\
Sedang $(20,440 \mathrm{Ha}-39,625 \mathrm{Ha})$ & 2 \\
Tinggi $(39,626 \mathrm{Ha}-58,811 \mathrm{Ha})$ & 3 \\
\hline
\end{tabular}

Sumber : Hasil pengolahan data, 2020

Penentuan kriteria penilaian ditentukan berdasarkan ketersediaan data di lapangan. Data dibagi ke dalam 3 standar kelas penilaian yang didapat dengan cara membandingkan data terbesar dan terkecil. Data selanjutnya dibagi dengan jumlah kelas yang akan dibuat.

\section{Parameter Kondisi Perumahan}

Parameter kondisi perumahan berdasarkan kepadatan perumah merupakan salah satu faktor untuk penentuan daerah prioritas. Kepadatan perumahan yang tinggi berarti jarak antar rumah sangat berdekatan, hal ini dapat menyulitkan akses untuk alat kumpul atau alat angkut beroprasi, sehingga semakin besar kepadatan rumahnya maka semakin urgensi daerah tersebut untuk dilayani. Berikut penilaian skoring parameter kondisi perumahan dapat dilihat pada Tabel 6.

Tabel 6. Parameter kondisi perumahan

\begin{tabular}{lc}
\hline \multicolumn{1}{c}{ Kriteria Penilaian } & Skor \\
\hline Kepadatan Perumahan & 1 \\
Rendah Kepadatan & 2 \\
Perumahan Sedang & 3 \\
Kepadatan Perumahan Tinggi & \\
\hline
\end{tabular}

Sumber : [2]

\section{Parameter Topografi}

Topografi merupakan salah satu faktor untuk penentuan daerah prioritas. Semakin datar topografinya semakin prioritas daerah tersebut, karena jika kemiringan lereng datar akan lebih mudah dikelola. Sehingga daerah dengan topografi yang datar merupakan daerah yang prioritas. Berikut penilaian skoring pada parameter topografi dapat dilihat pada Tabel 7.

Tabel 7. Parameter kondisi topografi

\begin{tabular}{lc}
\hline \multicolumn{1}{c}{ Kriteria Penilaian } & Skor \\
\hline Dominan bergelombang (9-40\%) & 1 \\
Sebagian besar dan & 2 \\
DominanDominan Datar $(0-8 \%)$ & 3 \\
\hline
\end{tabular}

Sumber : [2]

\section{Parameter Kondisi Lingkungan}

Kondisi lingkungan merupakan salah satu faktor untuk penentuan daerah prioritas. Dalam parameter ini yang dilihat ialah area beresiko persampahannya, semakin tinggi area beresiko persampahannya maka skor semakin tinggi dan semakin prioritas daerah tersebut. Penilaian skoring pada parameter kondisi lingkungan dapat dilihat pada Tabel 8. 
Tabel 8. Parameter kondisi lingkungan

\begin{tabular}{cc}
\hline Kriteria Penilaian & Skor \\
\hline Rendah & 1 \\
Sedang & 2 \\
Tinggi & 3 \\
\hline
\end{tabular}

Sumber : [5]

\section{Parameter Daerah Pelayanan}

Parameter daerah pelayanan merupakan salah satu parameter untuk penentuan daerah prioritas.

Daerah pelayanan yang dimaksud ialah daerah yang sudah atau belum pengelolaan sampahnya terlayani oleh suatu kota. Rendahnya presentase suatu daerah mengenai daerah pelayanan maka semakin prioritas daerah tersebut. Tabel 9 adalah klasifikasi penilaian skoring pada parameter daerah pelayanan.

Tabel 9. Parameter daerah pelayanan

\begin{tabular}{cc}
\hline Kriteria Penilaian & Skor \\
\hline Rendah $(0 \%-33 \%)$ & 1 \\
Sedang $(34 \%-44 \%)$ & 2 \\
Tinggi $(67 \%-100 \%)$ & 3 \\
\hline & Sumber : $[1]$ \\
\hline
\end{tabular}

\section{Parameter Daerah Pelayanan}

Parameter pendapatan penduduk merupakan salah satu faktor untuk menentukan daerah proritas. Pendapatan penduduk juga menentukan keberhasilan dari pengelolaan sampah di suatu daerah pelayanan kota. Hubungannya ialah terdapat pada jumlah timbulan sampah dan komposisi sampah yang dihasilkan. Penduduk dengan pendapatan rendah memiliki gaya hidup yang berbeda dengan penduduk pendapatan tinggi. Perbedaan gaya hidup tersebut penduduk dengan pendapatan tinggi akan lebih konsumtif sehingga akan menghasilkan volume sama sampah yang besar dibandingkan penduduk dengan pendapatan rendah. Sehingga semakin tinggi pendapatannya maka daerah tersebut merupakan daerah prioritas. Pembagian standar kelas ini dibuat berdasarkan nilai pendapatan tertinggi dikurangi nilai pendapatan rendah selanjutnya dibagi dengan kelas yang akan dibuat. Berikut penilaian skoring untuk parameter daerah pelayanan dapat dilihat pada Tabel $\mathbf{1 0}$.

Tabel 10. Parameter pendapatan penduduk

\begin{tabular}{lc}
\hline Kriteria Penilaian & Skor \\
\hline Rendah (Rp. 61.184,05 - Rp. 1.656.513,59) & 1 \\
Sedang (Rp 1.656.531,60 - Rp 3.251.843,14) & 2 \\
Tinggi (Rp3.251.843,14 - Rp4.847.172,68) & 3 \\
\hline
\end{tabular}

\section{Hasil dan Pembahasan}

\section{Daerah Pelayanan Sampah di Wilayah Bandung Utara}

Berdasarkan penelitian sebelumnya [2] yaitu "Identifikasi Daerah Pelayanan Sistem Pengelolaan Sampah di Wilayah Bandung Utara Menggunakan Metode Cluster Analysis", daerah pelayanan (cluster) di WP Bandung Utara terbagi menjadi enam. Pembagian daerah pelayanan ini dikelompokan berdasarkan karakteristik daerahnya menggunakan metode cluster analysis. Cluster analysis ini merupakan analisis statistika yang mengacu pada kesamaan atau homogenitas dari suatu data yang nantinya dikelompokan ke dalam 1 cluster. Berikut enam cluster yang telah dikelompokan berdasarkan metode cluster analysys, dapat dilihat pada Tabel 11.

Tabel 11. Daerah pelayanan sampah di wilayah Bandung Utara

\begin{tabular}{cl}
\hline Cluster & \multicolumn{1}{c}{ Kelurahan } \\
\hline 1 & Ciumbuleuit \\
& Ledeng \\
& Cigadung \\
\hline & Hegarmanah \\
& Dago \\
& Lebak Siliwangi \\
& Gegerkalong \\
\hline
\end{tabular}




\begin{tabular}{ll}
\hline Cluster & \multicolumn{1}{c}{ Kelurahan } \\
\hline & Isola \\
& Sukarasa \\
& Cipedes \\
& Sukabungah \\
& Sukawarna \\
& Cipaganti \\
& Lebak Gede \\
& Neglasari \\
& Sukaluyu \\
& Cicadas \\
& Padasuka \\
& Pasirluyung \\
& Sukamaju \\
& Sukapada \\
& Cihapit \\
& Citarum \\
& Sadang Serang \\
& Sekeloa \\
& Sukagalih \\
& Cikutra \\
& Sarijadi \\
\hline & Pasteur \\
& Tamansari \\
& Cihaurgeulis \\
\hline & Sumber : [2] \\
\hline &
\end{tabular}

\section{Analisa Pemilihan Daerah Pelayanan Sampah Prioritas}

Pemilihan daerah pelayanan sampah prioritas ini berdasarkan parameter pemilihan daerah prioritas pada SNI 19-2454-2002 tentang Tata Cara Teknik Pengelolaan Sampah Perkotaan. Pemilihan daerah prioritas ini bertujuan untuk menetukan daerah pelayanan sampah yang paling utama untuk dilakukan kajian lebih lanjut terkait sistem pengelolaan sampahnya. Berikut hasil rekapitulasi skoring penentuan daerah pelayanan prioritas dapat dilihat pada Tabel 12.

Tabel 12. Rekapitulasi skoring penentuan daerah prioritas

\begin{tabular}{|c|c|c|c|c|c|c|c|}
\hline No & Parameter & $\begin{array}{c}\text { Cluster } \\
1\end{array}$ & $\begin{array}{c}\text { Cluster } \\
2\end{array}$ & $\begin{array}{c}\text { Cluster } \\
3\end{array}$ & $\begin{array}{c}\text { Cluster } \\
4\end{array}$ & $\begin{array}{c}\text { Cluster } \\
5\end{array}$ & $\begin{array}{c}\text { Cluster } \\
6\end{array}$ \\
\hline 1. & Kepadatan penduduk & 1 & 2 & 2 & 2 & 2 & 3 \\
\hline 2. & Jalan arteri & 1 & 1 & 2 & 2 & 2 & 3 \\
\hline 3. & RTH & 2 & 3 & 3 & 3 & 3 & 3 \\
\hline 4. & Industri & 1 & 1 & 1 & 1 & 3 & 1 \\
\hline 5. & Perdagangan dan jasa & 2 & 2 & 2 & 1 & 3 & 1 \\
\hline 6. & Kondisi perumahan & 1 & 1 & 1 & 3 & 1 & 2 \\
\hline 7. & Kondisi topografi & 2 & 3 & 1 & 2 & 3 & 2 \\
\hline 8. & Kondisi Lingkungan & 2 & 2 & 2 & 2 & 2 & 2 \\
\hline 9. & Daerah Pelayanan & 2 & 1 & 2 & 1 & 2 & 1 \\
\hline 10. & Pendapatan Penduduk & 1 & 2 & 2 & 2 & 2 & 1 \\
\hline & Total & 15 & 18 & 18 & 19 & 23 & 18 \\
\hline
\end{tabular}

Sumber : Hasil pengolahan data, 2020

Hasil rekapitulasi pada 10 parameter diatas menentukan daerah pelayanan terpilih nantinya, daerah yang terpilih merupakan cluster yang memiliki skor paling tinggi. Skor ini menandakan semakin tingginya skor maka daerah tersebut yang paling utama untuk dikaji lebih lanjut pengelolaan sampahnya. Hasil skoring dapat dilihat, maka daerah pelayanan prioritas untuk pengelolaan sampah di WP Bandung Utara adalah daerah cluster 5 karena cluster tersebut memiliki skor yang paling tinggi sehingga dapat disimpulkan bahwa cluster tersebut merupakan daerah prioritas yang terdiri dari Kelurahan Pasteur dan Tamansari. 


\section{Kesimpulan}

Berdasarkan hasil rekapitulasi dari penilaian penentuan daerah prioritas berdasarkan parameterparameter penentuan daerah prioritas pada SNI 19-2454-2002 tentang Tata Cara Teknik Pengelolaan Sampah Perkotaan maka didapatlah Cluster 5 sebagai daerah prioritas pelayanan sampah di Wilayah Bandung Utara, yang terdiri dari Kelurahan Tamansaari dan Kelurahan Pasteur. Pemilihan daerah prioritas ini didasarkan atas karakteristik daerahnya sehingga nantinya akan memudahkan perencanaan sitem pengelolaan sampahnya. Kelurahan Pasteur dan Tamansari memiliki nilai bobot paing tinggi sehingga perlu ditangani lebih lanjut untuk direncanakan sistem SPS-nya agar tidak terjadi permasalahan baru ketika sampahnya tidak dikelola dengan baik.

\section{Daftar Pustaka}

[1] P.D Kebersihan Kota Bandung, 2017

[2] Septiani,P. Identifikasi Daerah Pelayanan Sistem Pengelolaan Sampah di Wilayah Pelayanan Bandung Utara, 2018

[3] SNI 19-2454-2002 Tata Cara Teknik Pengelolaan Sampah Perkotaan,2002

[4] Damanhuri, E. dan Padmi, T. Pengelolaan Sampah Terpadu. Institut Teknologi Bandung, 2016

[5] Bappeda Kota Bandung. 2015. Laporan Penyusunan Pemutakhiran Stategi Sanitasi Kota Bandung.

[6] Damanhuri, E dan Padmi,Tri. 2010. Diktat Kuliah Pengelolaan Sampah. Bandung : Institut Teknologi Bandung

[7] Dharmasetiawan, M. 2006. Daur Ulang Sampah dan Pembuatan Kompos.Jakarta : Ekamitra

[8] Pemerintah Indonesia. 2012. Peraturan Pemerintah Republik Indonesia Nomor 82 Tahun 2012 tentang Pengelolaan Sampah Rumah Tangga dan Sampah Sejenis Rumah Tangga.

[9] Republik Indonesia. 2008. Undang-Undang Nomor 18 Tahun 2008 tentang Pengelolaan Sampah

[10] Badan Pusat Statistik. 2019. Kecamatan Sukajadi dalam Tahun Angka 2019

[11] Bandung, B.P.S.K 2018. Kota Bandung Dalam Angka 2019. Bandung Statistik Kota Bandung, Bandung

[12] Badan Pusat Statistik. 2019. Kelurahan Neglasari dalam Tahun Angka 2019

[13] Badan Pusat Statistik. 2019.Kelurahan Sukawanadalam Tahun Angka 2019

[14] Badan Pusat Statistik. 2019. Kelurahan Gegerkalongi dalam Tahun Angka 2019

[15] Badan Pusat Statistik. 2019. Kelurahan Tamansari dalam Tahun Angka 2019

[16] Badan Pusat Statistik. 2019. Kelurahan Pasteur dalam Tahun Angka 2019 